\title{
Abu Alkasem AL Zehrawi (Albucasis 936-1013)
}

\author{
Jalal Annajjar
}

Published online: 30 May 2009

(C) Springer-Verlag 2009

\section{"Without doubt Albucasis was the chief of all surgeons"}

\section{Pietro Argallata (died 1423)}

Before the Islamic era, surgery was considered inferior to medicine, and surgeons were held in lower grade. For the first time, surgery was identified as a distinct part of medicine by AL Zehrawi (see Fig. 1) and was called hand work or iron work. Indeed, the title of the 30th chapter of his impressive book Atasreef was On Surgery or Hand Work.

Albucasis could not have achieved his high knowledge level without having advanced the current medical fields and without having introduced new significant technical advances. For example, he devised the anesthetic sponge at a time when anesthetic solutions were given as multidoses to the patient to make him unconscious for surgery with the risk of overdosage. Al Zehrawi was the first to use a sponge that steeped in aromatics and soporific and dried to be moistened when required and applied to patient's lips and nostrils. This Arabic innovation consisted in immersing the anesthetic sponge in a boiled solution (Fig. 2) made of water with hashish (from Arabic hasheesh), opium (from Arabic afiun), c-hyoscine (from Arabic cit al huscin), and zo'an (Arabic for wheat infusion). The dried sponge acted as a carrier for the active ingredients after the solution evaporation. Anesthesia by inhalation was called Arabian Nights.

J. Annajjar $(\square)$

Arkansas Research Fellowship,

Secretary of Syrian Society of Neurological Surgeons,

WFNS Education and Training Committee,

P.O. Box 1707, Homs, Syria

e-mail: jalalsurgeon@yahoo.com
Albucasis was a pioneer in developing surgical instruments. In his encyclopedia, he introduced more than 200 pictures of surgical tools with related descriptions and instructions on the way to use them (Figs. 2 and 3). He certainly experienced, during the numerous craniotomies he performed, the acciden-

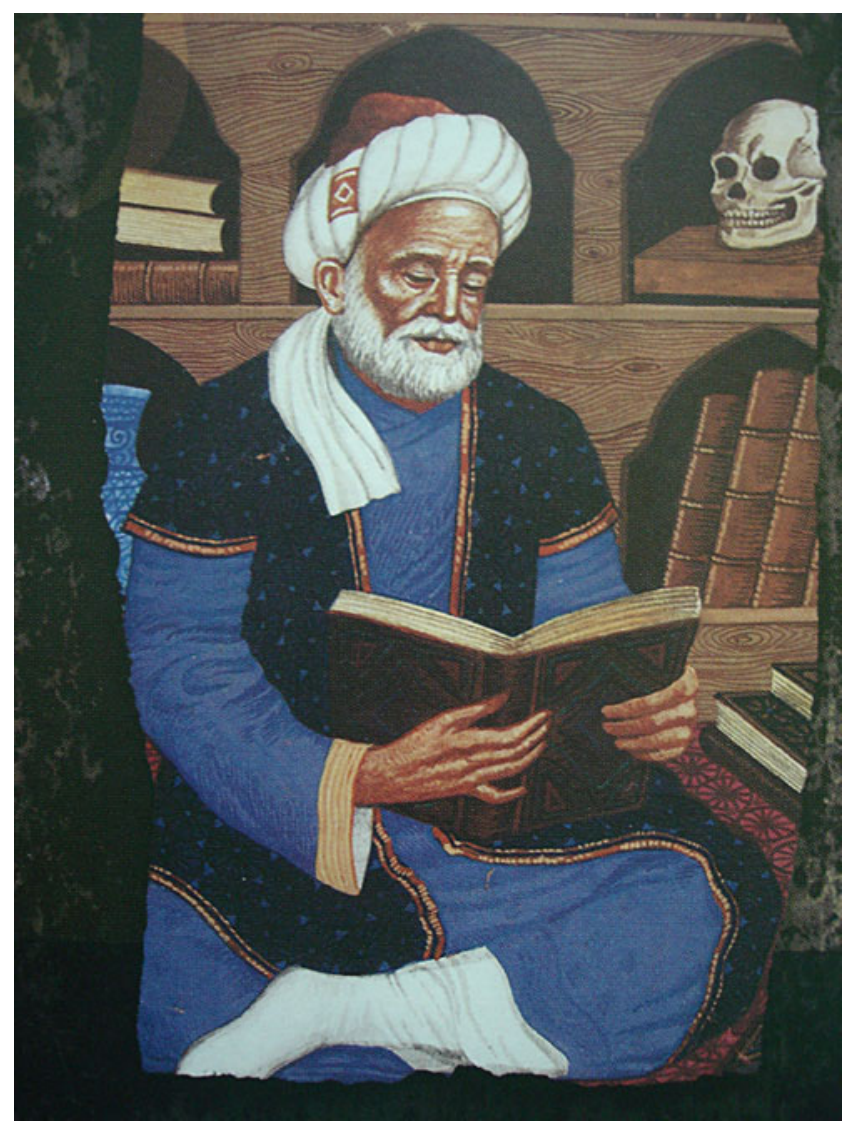

Fig. 1 Portrait of Abu Alkasem AL Zehrawi (Albucasis 936-1013), used as cover illustration 
Fig. 2 Portrait of Albucasis using his anesthetic sponge during surgery, by Dr. Qatay, original manuscripts AL Assad Library, Damascus, Syria

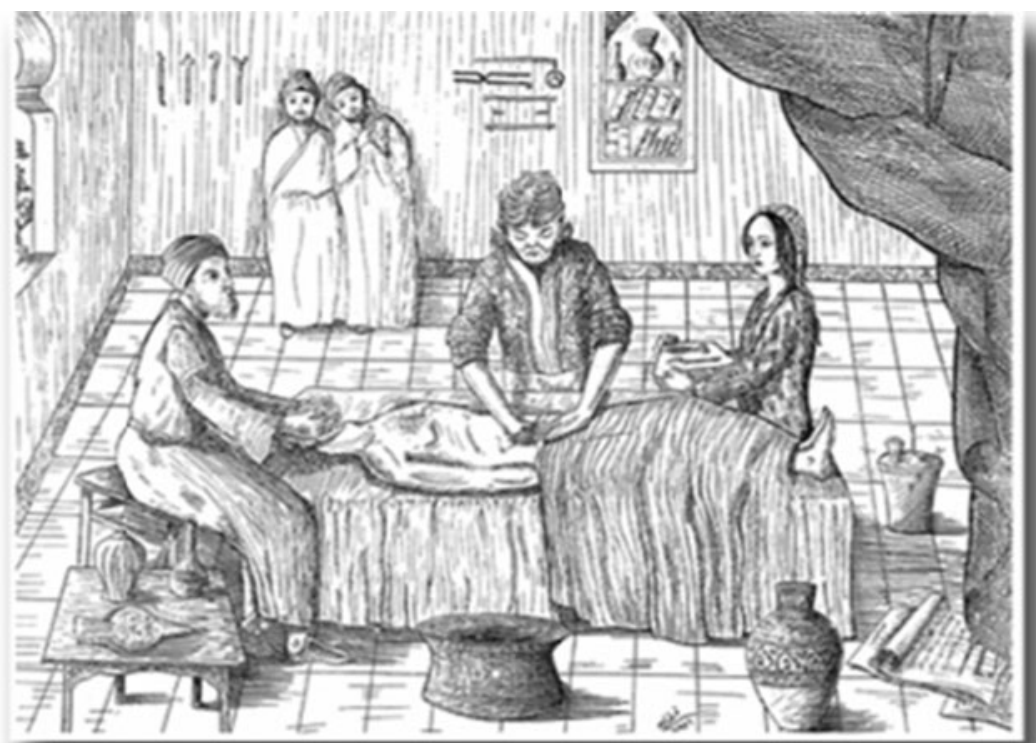

Fig. 3 Surgical tools devised or utilized by Albucasis Abu'l Qasim al-Zahrawi's eleventh century medical encyclopedia: Kitab al-Tasrif. Chapter 30 On Surgery, Hand work

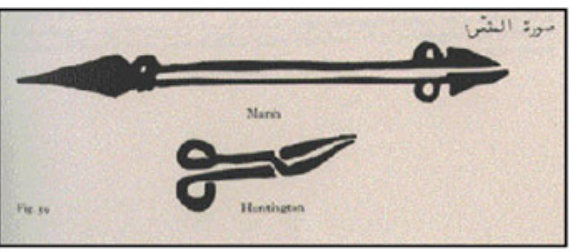

Concealed knife.

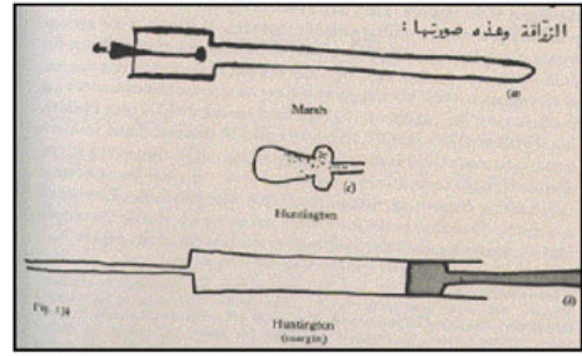

Syninge.
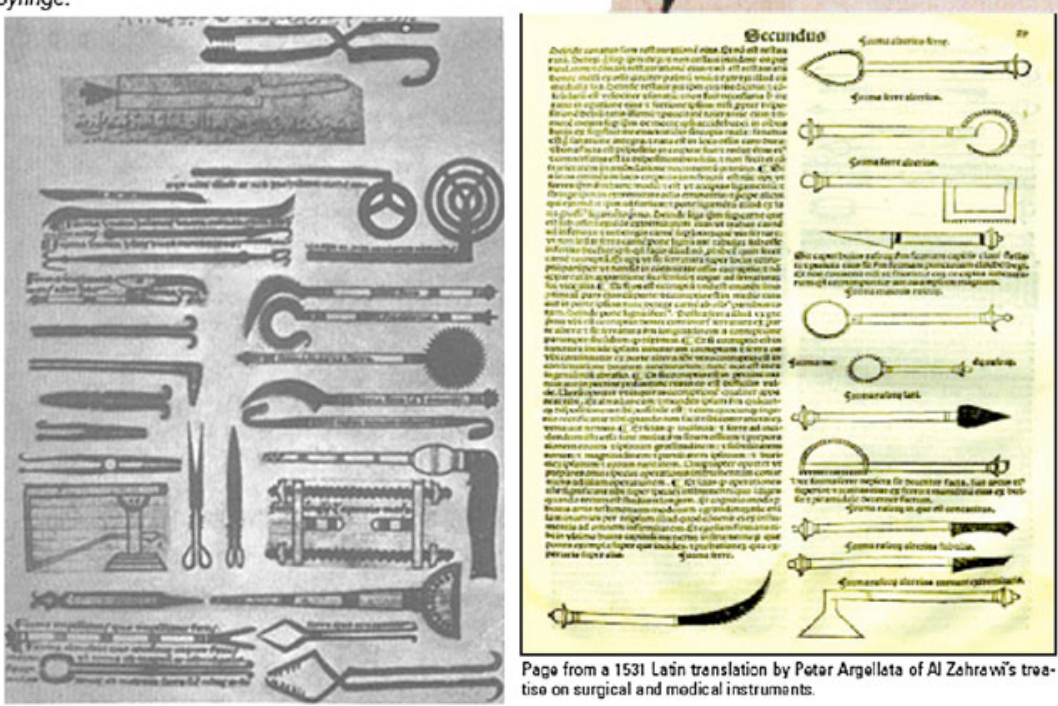
tal dural tearing and brain penetration as he was the first to introduce a nonsinking skull trephine for skull access, using a circular metal margin to avoid plunging into the brain tissue and laceration of the dura and brain tissue.

Albucasis was the first to use surgical cotton, cat gut for internal suturing, and thermal cauterization to stop vessel bleeding.
(As the Arab scholars had used the Greek candles for their lamps, but they rapidly became a huge Flambeau giving its light to all world, William Osler)

In Sigrid Hunke, Allas Sonne über dem Abendland: Unser Arabisches Erbe, Arabic version translated from German by F. Bydon 1963. 